\title{
Research on the Influencing Mechanism of Vlog Content Marketing on Consumer's Brand Identity and Purchase Intention
}

\author{
Ximing $\mathrm{Li}^{1, *}$ Jiaxin Zheng ${ }^{2}$ \\ ${ }^{1}$ Beijing Institute of Technology, Zhuhai, Zhuhai, Guangdong 519085, China \\ ${ }^{2}$ Macau University of Science and Technology, Macau, China \\ *Corresponding author. Email: liximing19027@163.com
}

\begin{abstract}
With the advent of the $5 \mathrm{G}$ era, the Vlog social mode has also ushered in a third form. Branding businesses keep up with the times and gradually shift their marketing methods from traditional media to Internet media. They use content marketing in Vlog to interfere with consumers' brand identity and affect consumers' purchase intentions ultimately. Combining with the three-stage theoretical influence factor model of content marketing, this paper takes Vlog users as the research objects, and carries out the research from multiple dimensions of functional content, entertainment content, social interactive content, brand engagement content, self-actualization content, and emotional content. Also, this paper explores the heterogeneous tendency of the sample groups in purchase intention, analyzes the correlation and influence mechanism between brand identity and purchasing intention, and finally puts forward countermeasures and suggestions.
\end{abstract}

\section{Keywords: Vlog content marketing, consumer, brand identity, purchase intention}

\section{INTRODUCTION}

According to "the statistical report on the development of China's Internet (CNNIC)", as of June 2019, China's online video users reached 759 million, an increase of 33.91 million compared with that at the end of 2018 , accounting for $88.88 \%$ of the total Internet users. The number of short video users is 648 million, accounting for $75.8 \%$ of the total Internet users. Short video is popular with the public, and the short video platform has begun to explore new business models. The major e-commerce platforms introduce short video content in the form of independent short video channels or applications, and use its features of being real and intuitive to help users quickly understand the goods, so as to achieve the purpose of shortening the consumption decision-making time, and attracting users to buy. At the same time, the platforms cooperate with ecommerce to improve user accounts and attract users to purchase goods directly in short video applications, forming a closed-loop transaction within the platform. Then, the purchase intention can be transformed into purchase behavior, the consumption time can be shortened, and the consumption can be developed. With the advent of $5 \mathrm{G}$ era, the market scale of Vlog will

*Fund: Scientific Research Project of Guangdong Provincial Department of Education — "Welfare, People's Livelihood and Design Service: Research on the Future Lifestyle in the Villages of Guangdong Province" (2019KZDZX2029). continue to grow steadily in the future. In 2019, the number of Vlog users in China reached 249 million. At present, Vlog is added to the internal industrial chain of major video social platforms to prepare for the development of Vlog industry in advance. As the next outlet of video social contact, Vlog has attracted the attention of numerous brands.

The essence of Vlog business promotion is content marketing. This paper takes the new form of content marketing - Vlog, as the research object. At the same time, this paper takes Vlog users as the research objects. Based on the theories of "use and satisfaction", "symbolic interaction theory" and "third-party effect", this paper interprets the purchase intention, understands the influencing factors of brand identity in content marketing, and studies the relationship between brand identity and purchase intention. Therefore, the research has high practical significance and social commercial value.

Taking the consumer groups in Vlog content marketing as the sample, this paper intends to explore the following three aspects: first is to explore consumers' cognition of Vlog content marketing and the heterogeneity tendency of purchase intention among groups based on demographic variables. Second is to discuss the relationship among functional content, entertainment content, social interaction content, brand interaction content, self-practice content, emotional 
content and brand identity. Third is to explore the influence mechanism of brand identity and purchase intention of Vlog users and its significance.

\section{LITERATURE REVIEW}

\section{A. Theoretical basis}

1) Research on the relationship between brand identity and purchase intention: Lastovicka and Gaedner (1979) pointed out in their research that people's sentimentality or attitude towards a brand is the public's brand identity to the brand, and this brand identity can be used as a set of variables to measure consumers' purchase intentions, which will ultimately affect consumers' buying behavior. This research defines the relationship between consumers' brand identity and their purchase intentions.

2) Research on the relationship between content marketing and brand identity: Jonah Berger (2009) pointed out in the research that content marketing is not a direct factor that affects consumers' buying behavior. This kind of transmission mechanism can be understood or explained as that after consumers receive information derived from content transmission, they will have two completely different emotional experiences. These two emotional experiences are positive emotions and negative emotions. Furthermore, these two completely different emotional experiences will form a different state called "high emotional arousal", which includes multiple elements such as joy, anger, tension, and relaxation. Different "high emotional arousal" will induce consumers' purchase and active communication intentions with different orientations. This mechanism is the three-stage model of "content - emotion - behavior". Later, Sun Tianxu (2016) extended the connotation of the three-stage model of "content - emotion - behavior" in his research, forming a three-dimensional model of dynamic brand relationship, namely, cognition (content) — emotion (brand identity) ) - behavior (purchase intention).

3) Research on the dimensional content of content marketing: Based on Gutman's MEC (1982), Fu Huifen and Lai Yuanwei (2016) tested and defined the five dimensions of brand content marketing strategy through empirical research, namely, functional information content, entertainment information content, brand interaction content, social interaction content and selfactualization content. Based on the research results of Fu Huifen and Lai Yuanwei (2016), Gao Danli (2019) further verified and confirmed that there is a significant positive relationship among the five dimensions that constitute a brand's content marketing strategy and consumers' brand identity, that is, there is a positive correlation between consumers' purchase intention and consumers' brand identity. At the same time, Sun Tianxu (2016) proposed that content marketing includes three dimensions of information-based content marketing, entertainment-based content marketing, and emotional content marketing based on the TRA and the three-stage model of content marketing.

\section{B. Definition of Vlog and content marketing}

1) Definition of Vlog: Vlog (Video Blog) originated from the YouTube website of the United States. The official definition of Vlog by YouTube is that Vlog uses videos to record daily life, that is, a video log. The creator uses colloquial language to communicate with the audience through the lens. The format and type of the videos are casual. This paper defines Vlog as a way for humans to use photography and video equipment to record life. The creator can be everyone, and its content ranges from daily life to travel, food, introduction to the objects, personal reflection, etc., showing personal consciousness and life attitude. The creators can gain attention and benefits, and users can broaden their horizons, acquire new knowledge and reflect on their own lives.

2) Definition of content marketing: The Content Marketing Institute defines content marketing as a strategic marketing tool that focuses on creating and disseminating valuable, relevant and continuous content, thereby attracting and retaining the clearlydefined audiences and making a profit. Zhang Meijuan and Liu Fangming (2017) proposed that content marketing is to use various media platforms (Weibo, WeChat) to deliver the brand concept of products or brands through the form and creativity that are close to consumers, and to provide target consumers with the required information. Its purpose is to enhance corporate brand equity and promote sales. Based on the above definitions, this study believes that VLOG content marketing uses VLOG as a new channel. As an intermediate host, Vlogger provides audiences with valuable information, while corporate and brand information can be effectively disseminated, forming a win-win situation.

\section{RESEARCH DESIGN}

\section{A. Research model construction}

Through sorting, summarizing and deducting relevant literature, the research finally formed a multidimensional structure model with consumers' purchase intention as the constructs, consumers' brand identity and content marketing as the dimensions, functional content, entertainment content, social interaction 
content, brand interaction content, self-actualization content and emotional content marketing as the factors. At the same time, it is to set up three control variables and demographic variables, namely, gender, age and educational background (as shown in "Fig. 1").

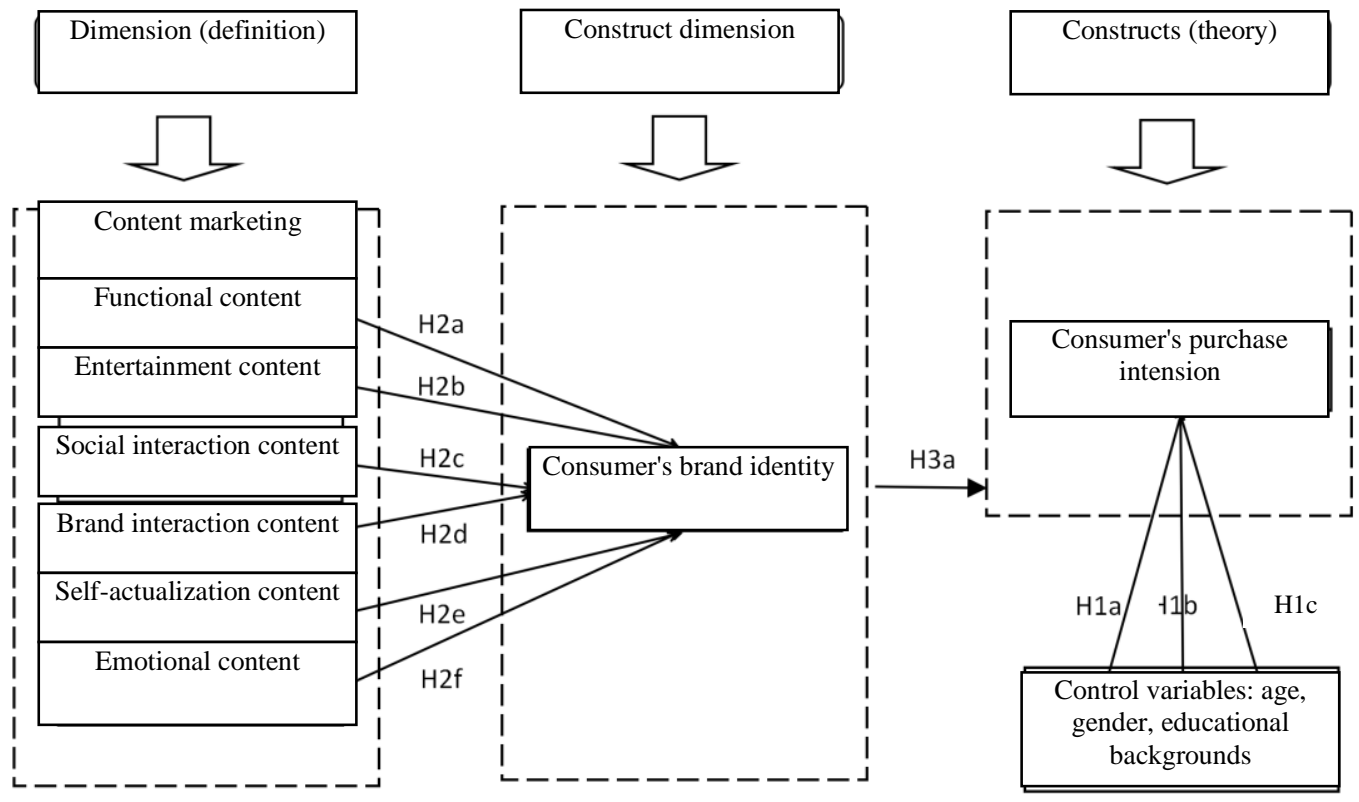

Fig. 1. The theoretical model framework of this study.

\section{B. Research hypothesis}

According to the first research question, it is suggested to explore consumers' cognition of Vlog content marketing and the heterogeneity tendency of purchase intention among groups based on demographic variables. The following assumptions are made:

H1a. There are significant differences among users of different genders in purchase intentions;

H1b. There are significant differences among users of different ages in purchase intentions;

H1c. There are significant differences among users with different educational backgrounds in purchase intentions.

According to the second research question, it is suggested to explore the relationship among functional content, entertainment content, social interaction content, brand interaction content, self-actualization content, emotional content and brand identity. The following assumptions are made:

H2a. There is a significant correlation between functional content and user's brand identity;

$\mathrm{H} 2 \mathrm{~b}$. There is a significant correlation between entertainment content and user's brand identity;
$\mathrm{H} 2 \mathrm{c}$. There is a significant correlation between social interaction content and user's brand identity;

$\mathrm{H} 2 \mathrm{~d}$. There is a significant correlation between brand interaction content and user's brand identity;

$\mathrm{H} 2 \mathrm{e}$. There is a significant correlation between selfactualization content and user's brand identity;

H2f. There is no correlation between emotional content marketing and user's brand recognition.

According to the third research question, it is suggested to explore the influence mechanism of Vlog users' brand identity and their purchase intention and its significance. The following assumptions are made:

H3a. The user's brand identity has a significant impact on the purchase intention.

\section{Questionnaire design and data collection}

In order to ensure the scientificity of the scale, the questionnaire design fully refers to the mature scale of past researches. The questionnaire is divided into four parts. The first part is on the control variables. It is composed of demographic variables (gender, age, education), and 3 items are set up. The second part is on the theory of consumer's purchase intention constructs, and 6 operational definition questions. The third part is on the concept of consumer's brand identity, and there are 8 operational definition items. The fourth part is on the element indicators under the content marketing 
dimension, consisting of 4 questions of functional content, 3 questions of entertainment content, 3 questions of social interaction content, 2 questions of brand interaction content, and 3 questions of selfactualization content and 3 questions of emotional content marketing. The questionnaire contains 35 questions, in which there are 3 questions on control variable and 32 questions on intensity variable. The intensity variable is set by using the Richter scale paradigm, namely, "1 refers to completely disagree, 2 refers to disagree, 3 refers to being uncertain, 4 refers to agree, and 5 refers to completely agree". Questionnaires were generated through the questionnaire star and distributed through Internet. In the end, 291 copies were returned, 21 unreasonable copies were eliminated, and 270 copies were valid, with an effective rate of $92.8 \%$.

\section{EMPIRICAL ANALYSIS}

\section{A. Demographic statistics}

The analysis results of the control variables, such as demographic statistics, in the sample data show that the proportion of men and women in the sample is $14.1 \%$ and $85.9 \%$, respectively, and the data shows an imbalance in the ratio of men and women. This is related to the source of the data sample group, for example, there are colleges and universities with liberal arts majors as the main body, and the fan group of bloggers with a large number of female fans. From the perspective of age distribution, the proportion of users aged 20-30 is the largest (221 people), accounting for $81.9 \%$. Followed by users under the age of 20 years old, the total number is 36 , accounting for $13.3 \%$. Other age groups account for less. The data shows that the age level of Vlog users is concentrated in the group aged 20-30. From the perspective of the distribution of educational backgrounds, they are mainly concentrated in undergraduates, with a total of 209 people, accounting for $77.4 \%$. Followed by the bachelor degree or below, there are a total of 34 people, accounting for $12.6 \%$, less users with educational backgrounds. In general, the gender ratio of the sample data is relatively reasonable, and the age distribution is also in line with the characteristics of the age distribution of Vlog consumer groups. With the use of this sample for subsequent statistical analysis of data, it can basically meet the needs of research reliability.

\section{B. Reliability and validity analysis}

1) Reliability analysis: Reliability testing relies on the reliability of the Cronbach Alpha Coefficient to judge the scale. It can be seen from "Table I" that $\alpha$ coefficients at all levels are good, indicating that the scale used in the study has a high level of reliability.

2) Validity analysis: The study uses exploratory factor analysis to test the validity of conceptual items at all levels. As shown in "Table I", the KMO index for all levels of items is good, indicating that the research scale has high construct validity.

TABLE I. RELIABILITY AND VALIDITY TEST PARAMETERS OF THE SCALE

\begin{tabular}{|l|l|l|l|l|l|}
\hline \multirow{2}{*}{ Item } & \multicolumn{1}{|c|}{ Reliability index } & \multicolumn{3}{c|}{ Validity index } & Number \\
& $\begin{array}{l}\text { standardization } \alpha \\
\text { coefficient }\end{array}$ & KMO index & $\begin{array}{l}\text { The approximate } \\
\text { chi-square }\end{array}$ & $\begin{array}{l}\text { significance } \\
\text { index }\end{array}$ \\
\hline consumer's purchase intention & 0.977 & 0.906 & 3107.823 & .000 & 32 \\
\hline consumer's brand identity & 0.973 & 0.909 & 2472.511 & .000 & 26 \\
\hline
\end{tabular}

\section{Difference test}

There are differences among consumers of different genders in purchase intentions. With the use of independent sample $\mathrm{T}$ test, the mean equation $\mathrm{T}$ value is 0.901 , the significance level is 0.368 , and there is no significant difference, which don't support the hypothesis H1a. There are differences among consumers of different ages in purchase intentions. As shown in "Table II", the variance F value is 1.811 , the significance level is 0.146 , and there is no significant difference, which don't support the hypothesis H1b. There are differences among consumers with different educational backgrounds in purchase intentions. With the use of one-way variance, the variance $F$ value is 0.896 , the significance level is 0.444 , and there is no significant difference, which don't support hypothesis H1c. It shows that there is no significant difference in consumer purchase intention among groups of different genders, ages, and educational backgrounds, and there is a trend of homogeneity. The purchase intentions of men and women, people of different ages, and consumers with different educational backgrounds are similar. 
TABLE II. ANALYSIS OF DIFFERENCES IN THE GROUPING OF DEMOGRAPHIC INDICATORS OF WILLINGNESS TO CONTINUE SHARING

\begin{tabular}{|c|c|c|c|c|c|c|c|c|c|}
\hline \multirow{2}{*}{\multicolumn{3}{|c|}{ Item }} & \multicolumn{3}{|c|}{$\begin{array}{l}\text { Variance equation's } \\
\text { levene }\end{array}$} & \multicolumn{4}{|c|}{ The $t$ - test of mean equation } \\
\hline & & & \multirow{2}{*}{$\begin{array}{l}\mathrm{F} \\
3.378\end{array}$} & \multicolumn{2}{|c|}{ Sig } & \multicolumn{2}{|l|}{$\mathrm{t}$} & \multirow{2}{*}{$\frac{\mathrm{df}}{268}$} & \multirow{2}{*}{\begin{tabular}{|l|}
$\begin{array}{l}\text { Sig. } \\
\text { sided) }\end{array}$ \\
0.368 \\
\end{tabular}} \\
\hline \multirow{2}{*}{$\begin{array}{l}\text { grouping by } \\
\text { gender }\end{array}$} & \multirow{2}{*}{\multicolumn{2}{|c|}{$\begin{array}{l}\text { it is assumed that the variances are equal } \\
\text { it is assumed that the variances are not equal }\end{array}$}} & & \multicolumn{2}{|c|}{0.067} & \multicolumn{2}{|c|}{0.901} & & \\
\hline & & & & & & \multicolumn{2}{|c|}{0.773} & 45.235 & 0.444 \\
\hline \multirow{4}{*}{$\begin{array}{l}\text { grouping by } \\
\text { age }\end{array}$} & & quadratic sum & \multicolumn{2}{|l|}{$\begin{array}{l}\text { Degree } \\
\text { freedom }\end{array}$} & \multicolumn{2}{|c|}{ mean square } & \multicolumn{2}{|l|}{$\mathrm{F}$} & significance \\
\hline & Between-group & 3.679 & \multicolumn{2}{|l|}{3} & \multicolumn{2}{|c|}{1.226} & \multicolumn{2}{|c|}{1.811} & 0.146 \\
\hline & intra-group & 180.183 & \multirow{2}{*}{\multicolumn{2}{|c|}{$\frac{266}{269}$}} & \multicolumn{2}{|l|}{0.677} & & & \\
\hline & Total & 183.863 & & & & & & & \\
\hline \multirow{4}{*}{$\begin{array}{l}\text { grouping by } \\
\text { educational } \\
\text { background }\end{array}$} & & quadratic sum & \multicolumn{2}{|l|}{$\begin{array}{l}\text { Degree } \\
\text { freedom }\end{array}$} & \multicolumn{2}{|c|}{ mean square } & \multicolumn{2}{|l|}{$\mathrm{F}$} & significance \\
\hline & Between-group & 1.840 & \multirow{2}{*}{\multicolumn{2}{|c|}{$\frac{3}{266}$}} & \multicolumn{2}{|c|}{0.613} & & 0.444 \\
\hline & intra-group & 182.023 & & & & \multicolumn{2}{|c|}{0.896} & \\
\hline & Total & 183.863 & \multicolumn{2}{|l|}{$\frac{266}{269}$} & \multicolumn{2}{|l|}{0.684} & & & \\
\hline
\end{tabular}

\section{Correlation analysis}

The correlation coefficients of between functional content, entertainment content, social interaction content, brand interaction content, self-actualization content, emotional content and brand identity are 0.503 ,
$0.558, \quad 0.687,0.752,0.701,0.801$, and the corresponding $\mathrm{P}$ values are all 0.00 , which is less than the significance level of 0.01 , showing that there is the correlation, and the correlation coefficient is statistically significant. After verification, $\mathrm{H} 2 \mathrm{a}, \mathrm{H} 2 \mathrm{~b}$, $\mathrm{H} 2 \mathrm{c}, \mathrm{H} 2 \mathrm{~d}, \mathrm{H} 2 \mathrm{e}, \mathrm{H} 2 \mathrm{f}$ are supported. ("Table III")

TABLE III. SUMMARY OF CORRELATION

\begin{tabular}{|c|c|c|c|c|c|c|c|c|}
\hline & Function & Entertainment & $\begin{array}{c}\text { Social } \\
\text { interaction }\end{array}$ & $\begin{array}{c}\text { Brand } \\
\text { interaction }\end{array}$ & $\begin{array}{c}\text { Self- } \\
\text { actualization }\end{array}$ & Emotion & $\begin{array}{l}\text { Brand } \\
\text { identity }\end{array}$ & $\begin{array}{l}\text { Purchase } \\
\text { intention }\end{array}$ \\
\hline Function & 1 & 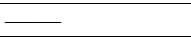 & - & - & ${ }^{-}$ & 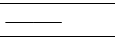 & - & 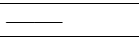 \\
\hline Entertainment & $.652 * * *$ & 1 & $\longrightarrow$ & $\longrightarrow$ & $\longrightarrow$ & $\longrightarrow$ & $\longrightarrow$ & $\longrightarrow$ \\
\hline Social interaction & $563 * * *$ & $.569 * * *$ & 1 & $\longrightarrow$ & $\longrightarrow$ & 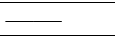 & 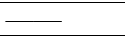 & $\longrightarrow$ \\
\hline Brand interaction & $.461 * * *$ & $.436 * * *$ & $.687 * * *$ & 1 & - & $\longrightarrow$ & - & - \\
\hline Self-actualization & $.512 * * *$ & $.474 * * *$ & $.625 * * *$ & $.684 * * *$ & 1 & - & 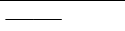 & 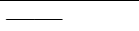 \\
\hline $\begin{array}{l}\text { The emotional } \\
\text { type QG }\end{array}$ & $.497 * * *$ & $.494 * * *$ & $.612 * * *$ & $.737 * * *$ & $.664 * * *$ & 1 & - & - \\
\hline Brand identity & $.503 * * *$ & $.505 * * *$ & $687 * * *$ & $.752 * * *$ & $.701 * * *$ & $.801 * * *$ & 1 & $\longrightarrow$ \\
\hline Purchase intention & $.579 * * *$ & $.581 * * *$ & $.670 * * *$ & $639 * * *$ & $.575 * * *$ & $.721 * * *$ & $.781 * * *$ & 1 \\
\hline
\end{tabular}

a. ****significantly correlated at 0.01 level (two-sided)

\section{E. Regression analysis}

There is an analysis of the relationship between consumer's brand identity and their purchase intention. As shown in "Table IV", the model fits well (R square $=0.611$ ), and consumer's brand identity has a significant impact on purchase intention $(B=0.745$,
$\mathrm{T}=20.496, \mathrm{P}<0.01$ ), indicating that $\mathrm{H} 3 \mathrm{a}$ is supported. It shows that consumer's brand identity has a significant influence on purchase intention, and it has a positive influence, that is, the higher the consumer's brand identity, the stronger their willingness to buy the product.

TABLE IV. SUMMARY OF REGRESSION ANALYSIS COEFFICIENTS OF THE INFLUENCE OF CONSUMERS' PURCHASE INTENTION ON THEIR PURCHASE BEHAVIOR

\begin{tabular}{|c|c|c|c|c|c|c|c|c|c|c|}
\hline \multicolumn{3}{|c|}{ Model } & $\begin{array}{l}\text { Model's } \\
\text { Fitting }\end{array}$ & \multicolumn{2}{|c|}{$\begin{array}{c}\text { Independent variable } \\
\text { difference ANOVA }\end{array}$} & \multicolumn{3}{|c|}{ Regression analysis parameter } & \multicolumn{2}{|c|}{$\begin{array}{l}\text { hypothesis } \\
\text { verification }\end{array}$} \\
\hline & \multicolumn{2}{|l|}{ variable } & $\mathrm{R}$ square & F value & $\begin{array}{l}\text { significan } \\
\text { ce }\end{array}$ & $B$ value & $\begin{array}{l}\mathrm{T} \\
\text { valuelue }\end{array}$ & $P$ value & $\begin{array}{l}\text { hypoth } \\
\text { esis }\end{array}$ & $\begin{array}{l}\text { verificatio } \\
\mathrm{n}\end{array}$ \\
\hline \multirow{2}{*}{ model 1} & \multirow{2}{*}{$\begin{array}{l}\text { Purchase } \\
\text { Intention }\end{array}$} & $\begin{array}{l}\text { constant } \\
\text { (quantity) }\end{array}$ & \multirow{2}{*}{0.611} & \multirow{2}{*}{420.080} & \multirow{2}{*}{0.000} & .937 & 8.025 & .000 & \multirow{2}{*}{$\mathrm{H} 1$} & \multirow{2}{*}{ support } \\
\hline & & $\begin{array}{l}\text { Brand } \\
\text { identity }\end{array}$ & & & & .745 & 20.496 & .000 & & \\
\hline
\end{tabular}




\section{CONCLUSION}

People are currently in the age of social media and demassification, and the entertainment and pastimes of the new generation are different from that of the past. The era of social media has given birth to personal IPs with unique attributes such as "bloggers", "net celebrities", and "hosts". These personal IPs have refined the masses and contributed to the advent of the demassification era. Correspondingly, the marketing methods of brand owners have shifted from traditional mass media represented by television and movies to Internet media. As a new form of content marketing, Vlog has had strong communication vitality and commercial value since its inception. It is necessary to make the exploration on how Vlogger attract audiences or consumers, how to cater to the demands of brand owners, and how to make media content and brand products closer. The "resonance" based on cooperation has become the focus of the business or culture. Therefore, the following two suggestions are put forward for content providers and brand owners.

\section{A. Suggestions for content providers}

Based on the hypothesis $\mathrm{H} 2 \mathrm{a}$, the significant correlation between "functional content and user's brand identity" is supported. First, bloggers need to accurately position their own content creation, clarify the creative style and content attribute category, and provide targeted audiences and consumer groups who are attracted or distinguished by positioning with highquality information that is targeted and has positioning value; there is significant correlation between entertainment content and user's brand recognition", and $\mathrm{H} 2 \mathrm{~b}$ is supported. In the content field, it is suggested to enhance the value of information supply, take into account the interest of the content, and meet the entertainment needs of users, so as to achieve the entertainment function of the media. There is significant correlation between social interaction content and user's brand identity, and there is also significant correlation between brand interaction content and user's brand identity, so that $\mathrm{H} 2 \mathrm{c}$ and $\mathrm{H} 2 \mathrm{~d}$ are supported. In terms of the content interaction, content providers need to strengthen communication with fans to fully reflect the advantages of the two-way information flow of the Internet media and the UGC characteristics of the media, such as the matching and coordination of online activities and offline activities of fan groups and the social interaction with fans. In terms of emotional cultivation of the fan group, the establishment of exclusive columns increases communication and information collision, and enhances the fan's sense of belonging to the group. At the same time, in the process of cooperation and communication with brand owners, content providers should take the interests of the fan community as the leading element and fully strive for product benefits and value-added services for the fan community. While making the fan community become the home of fans, it also serves as a bridge between fans and brand owners. It is assumed that $\mathrm{H} 2 \mathrm{e}$ is supported, that is, there is a significant correlation between "self-actualization content and brand identity. When consumers watch videos from content providers, to a certain extent, the various standards defined by content providers will be used as objects of reference or imitation, the behavior and intention of using products will be consistent with that of the content providers, ie bloggers. Therefore, content bloggers should maintain a relatively high standard and quality in the procedures for shaping their own personal settings, and avoid vulgar and kitsch personal images or unsuitable lifestyles and conditions, so as to encourage audiences to make the imitation to meet their needs to improve their self-image. To a certain extent, content providers meet their pursuit of self-actualization.

\section{B. Suggestions for branding business}

$\mathrm{H} 2 \mathrm{a}$ and $\mathrm{H} 2 \mathrm{~b}$ are supported, there is a significant correlation between functional content and user's brand identity, and there is a significant correlation between entertainment content and user's brand identity. Fans accept the information from content providers based on the information they need or the entertainment appeal of the information. Therefore, in terms of cooperation between branding business and content providers, branding business should grasp whether the selected content provider's Vlogger's fan positioning is consistent with the brand's product positioning, analyze the degree of agreement between the fan group and the target consumer defined by the product. It strives to achieve precise selection and advertisement, and avoid the sharp increase in marketing costs caused by nonprecision cross-domain marketing. It is assumed that $\mathrm{H} 2 \mathrm{~d}$ is supported, and there is a significant correlation between brand interaction content and user's brand recognition. The communication and interaction between branding business and consumers in Vlog content marketing is significantly correlated to brand identity. Vlog is a third-party advertisement, and bloggers can serve as the communication bridge to achieve communication between branding business and consumers. Due to this transmission communication mode, there is a certain degree of "estrangement" between branding business and consumers. Therefore, branding business should ingeniously define the form in which their products and staff "exist" or "show" in the process of communication between content bloggers and fans, so as to realize a kind of a multi-dimensional communication mode "derived from" but not "limited to" content provider. It is assumed that $\mathrm{H} 2 \mathrm{f}$ is supported, there is a significant correlation between emotional content marketing and user's brand identity. It shows that Vlog content marketing stimulates consumers' emotions and then triggers consumers' 
brand identity. Finally, consumers have purchase intention. Therefore, it is necessary to realize the "resonance" between product information and consumer's emotions in the process of communication with consumers through content providers, which is also the focus and creative manifestation of content marketing. It is assumed that $\mathrm{H} 3 \mathrm{a}$ is supported, and there is a significant correlation between user's brand identity and purchase intention. Branding business need to communicate with content providers and bloggers in the early stage. The communication content should mainly focus on how to integrate the brand into the film and guide the fan group (consumers) to generate brand identity, so as to realize the sublimation of brand information from "hard promotion" to "soft advertisement". Through content marketing, the brand identity of consumers is enhanced, the purpose of enhancing consumers' willingness to buy is achieved, and the product sales is promoted.

\section{References}

[1] Jonathan Gutman. (1982). A means-end chain model based on consumer categorization processes. Journal of Marketing.

[2] Berger, J. A., \& Milkman, K. L. (2009). What makes online content viral?. Journal of Marketing Research, 49(2), 192-205.

[3] Lastovicka,J.L.,\&Gardner, D.M. (1979). Components of involvement. Attitude research plays for high stakes, 53-73.

[4] The 44th "Statistical Report on Internet Development in China", June 2019. (in Chinese)

[5] iiMedia Report - 2019 China Vlog Business Model and User Behavior Monitoring Report (in Chinese)

[6] Suo Yujie. Study on the Phenomenon of Video Blog (VLOG) from the Perspective of Communication [D]. Beijing Institute of Graphic Communication, 2019. (in Chinese)

[7] Fu Huifen, Lai Yuanwei. Social Media Content Marketing Strategy of Consumer Electronics Brands - Content Analysis of Lenovo, Huawei, HTC and Samsung's Brand Sites on WeChat [J]. Management Review, 2016, 28(10): 259-272. (in Chinese)

[8] Gao Danli. Research on the Influence of Social Media Content Marketing on Consumers' Brand Purchase Willingness [D]. Zhejiang Gongshang University, 2019. (in Chinese)

[9] Sun Tianxu. The Effect of Content Marketing on Consumers' Purchase Intention [D]. Harbin Institute of Technology, 2016. (in Chinese)

[10] Zhang Meijuan, Liu Fangming. Research on content marketing in the era of digital media [J]. Publishing Science, 2017, 25(02): 8-13+28. (in Chinese) 